\title{
Teacher Educators' Appropriation of TPACK-SAMR Models for 21st Century Pre-Service Teacher Preparation
}

\author{
Nyarai Tunjera, Cape Peninsula University of Technology, Cape Town, South Africa \\ Agnes Chigona, Cape Peninsula University of Technology, Cape Town, South Africa
}

\begin{abstract}
The study examined how teacher educators are appropriating technological, pedagogical, and content knowledge (TPACK) and substitution, augmentation, modification, redefinition (SAMR) frameworks in their pre-service teacher preparation programmes. To ensure rigor, quality, and preparedness of pre-service teachers, there is a need to articulate expectations around effective use of these frameworks together with contemporary teaching and learning theories at the pre-service teacher preparation level. One-on-one in-depth interviews and participant observations were conducted with eight (8) teacher educators. The findings revealed that teacher educators are appropriating technology in ways harmonious with their prevalent traditional teacher-centred teaching strategies at enhancement levels. The researchers recommend the adoption of technology integration frameworks and teaching and learning theory at policy making levels in pre-service teacher training institutions.
\end{abstract}

\section{KEYWORDS}

$21^{\text {st }}$ Century Education, $4 \mathrm{Cs}$, Constructivist, Pre-Service Teachers, SAMR, Teacher Educators, Teacher Preparation Programmes, Teaching with Technology, Technology Integration, TPACK

\section{INTRODUCTION}

The $21^{\text {st }}$ century is characterised by an influx of information from various sources. Technological advancements have made it increasingly easy to share and access this information almost instantly. This presents the education field with both a challenge and opportunity in the teaching practice. The challenge being not all the available information is useful or even meaningful, therefore the $21^{\text {st }}$ century requires that students acquire the $4 \mathrm{Cs}$ (communication, collaboration, critical thinking and creativity) on how to engage with the information and not just receive it. The mandate on educational institution is therefore to make use of technology-enhanced practices to facilitate acquisition of these skills.

The use of technology in education is largely accepted to be an integral and expected part of the teaching and learning experience in this digital age. Teachers' knowledge of technology, and how it is incorporated into the curriculum, is currently a major focus of research in teacher education. Motivated by the belief that technology has the potential to improve learning processes, the South 
African Education Department and donor agencies are currently investing in projects aimed at providing technology into schools. However, the potential of technology can only be realised in schools when it has been properly adopted and integrated in the teacher preparation programmes. Technology integration in teacher preparation is not fully understood as most studies give attention to the practice of pre-service teachers (PSTs) use of technology for education. There appears to be fewer studies that focus on teacher educators ${ }^{1}$ (TEs) practices especially in teacher preparation programmes and their ability to model effective teaching with technology. In this study, effective teaching is whereby a TE uses technology to motivate and engage students in their learning as they develop knowledge and relationships with their learners. This study, therefore, sought to explore TEs' teaching strategies in teaching with technology so as to understand their current practices, and further evaluate existing technology models TEs are using to effectively prepare PSTs to teach with technology in the $21^{\text {st }}$ century.

\section{BACKGROUND}

Preparing PSTs to appropriate technology use for teaching and learning is of paramount importance in this digital era. Many TEs are assertive of their use of technology in their personal lives, but they are hesitant in translating it into their professional practices. However, researchers have also indicated that PSTs are not adequately equipped with sufficient knowledge to integrate technology in teaching and learning (Chigona \& Chigona, 2013; Sang, Tondeur, Chai, \& Dong, 2014; Tondeur, Pareja Roblin, van Braak, Voogt, \& Prestridge, 2017; Voogt \& McKenney, 2017). Teaching with technology goes beyond mere acceptance of digital tools but should be purposefully applied in their daily practices to achieve teaching and learning goals (Tondeur et al., 2017). Even though many studies have proven technology is being effectively utilised in other sections of society, this does not always imply that the same effects are also realised in educational settings. Studies have revealed that pre-service teachers ${ }^{2}$ feel inadequately prepared to integrate technology in their future classrooms (Enochsson \& Rizza, 2009; Tondeur et al., 2012). While this may be due to several factors, it is believed that the quality of pre-service teachers' preparation in the use of technology for learning, strongly shapes how they view and use technology in their future practice. Tondeur et al. (2013, p. 242) suggested that: "technology should be infused into the entire PSTs curriculum so that they; (a) understand the educational reasons for using technology and (b) experience how technology can support teaching and learning across a variety of subject disciplines."

TPACK is viewed as the widely accepted model to account for teacher knowledge on how to effectively teach with technology. Researchers, however, reveal that PSTs are only being equipped with technology skills in isolation to the teaching methods and subject matter (Tondeur et al., 2017; Voogt \& Mckenney, 2017). Although the TPACK constructs may not have a universally accepted meaning, there seems to be some degree of agreement that there is need for educators to appropriate TPACK in their PSTs preparation program. Harris, Mishra, \& Koehler, (2009, p. 393) argue that many current technology integration strategies are techno centric, often omitting sufficient consideration of the dynamic and complex relationships among content, pedagogy, and technology. TPACK is envisaged as a useful conceptual framework to explain the kind of knowledge teachers need to appropriate digital technology (Mishra \& Koehler, 2006). TPACK encompasses the link between technological knowledge (TK), pedagogical knowledge (PK), and content knowledge (CK) (Mishra \& Koehler, 2006), that contribute to TE's knowledge needed to effectively integrate technology in teaching and learning. This research study acknowledges the seven constructs of TPACK i.e. TCK (Technological and Content knowledge), TPK (Technological and Pedagogical knowledge), TK (Technology Knowledge), CK (Content Knowledge), PK (Pedagogical Knowledge) and TPACK (Technological, Pedagogical, and Content Knowledge), however this study focuses on the constructs with technology as an element. Preparing PSTs to effectively teach with technology implies that TEs need to understand how to shape instructional practices in which technological, content and pedagogical knowledge are embedded. 
This is an important reason to explore how TEs are appropriating TPACK knowledge domains to develop effective 21 st century teachers.

The TPACK construct, however, focuses mainly on the integration of technology, content and pedagogy knowledge, but does not necessarily foretell the outcome of it. For this purpose, the researchers of this study, decided to complement TPACK with the Substitution Augmentation Modification Redefinition (SAMR) model as it actually predicts that the integration of technology at different levels yields certain outcomes. The SAMR model describes the process of adopting a technology from acquisition to a point when the art is incorporated into one's everyday practice, i.e. the art of appropriating digital technology into ones' teaching practice for targeted outcomes.

Figure 1 illustrates how the researchers are conceptualising the constructivist principles with TPACK and SAMR models. Constructivist proponents are of the notion that people learn by interacting with others in their environment. In an education perspective, students process and make sense of information by actively engaging with it, therefore they call for student-centered approaches which allow for students to participate in knowledge acquisition. The conceptual framework illustrates how TPACK-SAMR models informed by a constructivist theoretical underpinning progresses towards TPACKed ${ }^{3}$ educators. TPACKed (see Figure 1) is the term the researchers have coined to mean educators who transform learning through integrating technology to achieve learning goals in previously inconceivable ways. In other words, they are capable of using affordances of technology that orchestrate for flexible learning (Ally \& Tsinakos, 2014). Teaching effectively is the TE's cognition of student learning context, in particular how they learn, process information, what motivates or hinders their knowledge acquisition process (Shulman, 1986). This is significant in this study, as TEs' understanding of the ways in which students learn informs their selection of technology-enhanced instructional strategies that assist students in their acquisition of the 4Cs. Mishra and Koehler (2009) argue that effective technology integration for teaching requires understanding and negotiating the relations between the three knowledge domains: Technology, Pedagogy, and Content.

Figure 1. Conceptualising the constructivist with TPACK-SAMR models

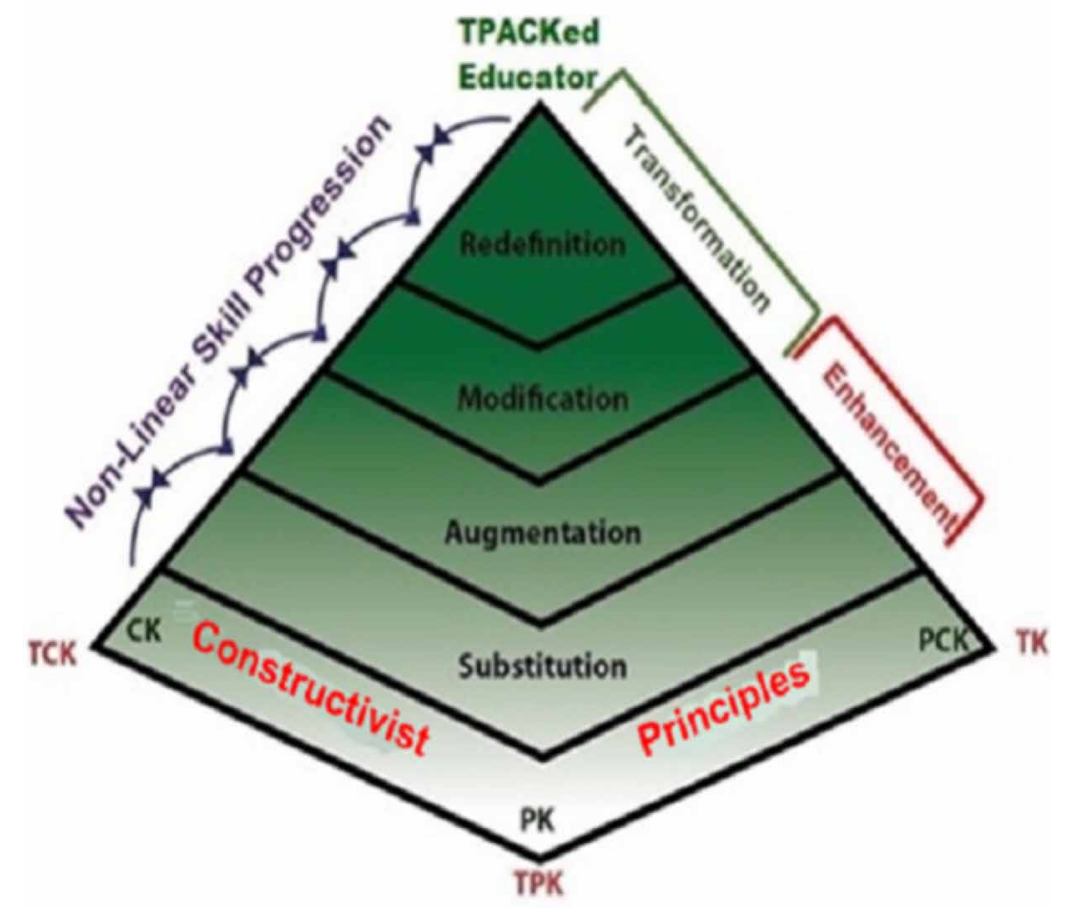


The TPACK framework highlights complex relations useful for defining what it is that teachers need to know to integrate digital technology effectively (Koehler \& Mishra, 2009). In their study, Mishra and Koehler (2006) recognise that many variables associated with technology integration in teaching and learning lie at the heart of this complex process. Central to this model, is the knowledge about relations between content, pedagogy and technology for developing effective student-centred learning in this digital age. On the other hand, the Substitution Augmentation Modification Redefinition (SAMR) model as presented by Puentedura (2009), shows an overview of the progression that adopters of digital technology often follow as they progress in their teaching with technology practices. The progression of TEs is shown by educators' ability to move from traditional teachercentred teaching activities to constructivist student-centred approaches enhanced with the new digital technologies. The researcher's combination of TPACK and SAMR models is beneficial in that, on its own, TPACK is formulated and focuses on the TEs and how they can integrate technology into their practice - the model was conceived from a behaviorist theoretical foundation. SAMR on the other hand, has a constructivist approach to it as it considers the students and how their learning process is impacted by technology integration. The study's conceptual framework therefore offers a holistic approach to the phenomena of teaching with technology in teacher training institutions by focusing on both educator and students' interaction with technology-enhanced teaching and learning activities.

TPACK and SAMR models have significant similarities; both models are mostly used to guide the planning, assessment and evaluation of technology use in teaching and learning (Kihoza, Zlotnikova, Bada, \& Kalegele, 2016). Technology is interwoven into both pedagogy and content as an element that facilitates the development of $21^{\text {st }}$ century skills. Both models, in isolation are limited in offering practical guidance on how to integrate all knowledge domains and how to use them in progressing towards the transformation of teaching activities.

To sum up, the researchers realised that TPACK and SMAR constructs, while contemporary and relevant to $21^{\text {st }}$ century education, where not complete in their own; one focused merely on the TEs technology knowledge, the other on technology-enhanced learning outcomes. The foundation of the conceptual framework - the constructivist teaching and learning theory is meant to direct TE's toward more modern student-centered approaches in teaching with technology. The conceptual framework implies that TE's should not use technology for the sake of it, but rather they should be informed by their teaching objectives.

\section{METHODOLOGY}

A qualitative research approach was employed to gather and analyse information from purposively sampled TEs from a teacher training institution. The qualitative case study adopted an interpretative paradigm which was considered appropriate for the goal of this paper which sought to acquire detailed information on the phenomenon of interest. The case study research method used one-onone interviews and was compounded with non-participant observation of the TE's practice during lectures. This research method was found appropriate to have an in-depth understanding of TEs in their natural setting as the researchers sought to make sense of and interpret pre-service teachers' preparation to teach with technology (Yin, 2003). Furthermore, this inquiry allowed the researchers to give close attention to the individual contexts and underlying logic of TEs assertions. Eight TEs participants were purposively selected based on them using technology in their lectures. The collected data was further analysed thematically.

\section{Participants}

An online survey was sent to sixty-three TEs from a faculty of teacher education in Western Cape, South Africa. The survey was employed to conveniently identify participants who were using technology in their current practices. The researchers were only interested in exploring and understanding what teaching strategies TEs were using in their teacher preparation programmes with regards to teaching 
with technology across all subject disciplines. The online survey consisted of Likert scale questions on TEs ability to use applications for teaching, access the internet for research and communication. Twenty-two responded, and ten TEs were purposively identified as prospective participants as they indicated that they use technology in their teacher preparation programmes. Eight of the ten TEs volunteered to participate in the study. All eight of them were various teaching phases, i.e. Foundation phase (FP) - constitutes training to teach from pre-school to grade 3 levels; General Education and Training (GET) training to teach from grade 4 - 9; and Further Education and Training (FET) training to teach grade $10-12$.

Figure 2 shows the participating TEs' qualifications, phases and respective subjects.

While all eight participants were interviewed only four agreed to be observed during lectures.

\section{Data Collection}

The researchers employed semi-structured one-to-one in-depth interviews and lecture observation data collection methods. The interviews comprised of open-ended questions derived from the conceptual framework and literature on integrating technology and some unique technological aspects in PSTs preparation. Examples of questions were, "what pedagogical strategies are you using in preparing PST to integrate technology?' 'How are you using technology to teach concepts in your discipline?' The interviews which were conducted from the TEs offices, as per their requests, took between thirty minutes and one hour and were recorded and transcribed verbose to capture information as it was given.

The researcher first obtained approval from the research ethics committee and gatekeepers to conduct the research. TEs were then approached by the researcher to discuss the purpose of the study and to seek their consent for completing the online survey and also to participate in the one-on-one in-depth interviews. Ten participants indicated their interests in participating in the study by ticking an option on the online survey. Eight voluntarily participated in the study. The researcher explained the purpose of the study to participants. Data was collected over an eight months' period from 2016 to 2017.

\section{Semi-Structured One-on-One Interviews}

The TEs were interviewed one-on-one using a semi-structured interview (see Appendix). This method was chosen to enable the researchers to explore their own explanations and motivations in their appropriation of theory and technology integration frameworks. Semi-structured interviews

Figure 2. Participants' qualifications, phases and respective subjects

\begin{tabular}{|l|l|l|l|}
\hline Code & Qualifications & Phase & Subject \\
\hline TE1 & Doctorate & GET & Mathematics \\
\hline TE2 & Doctorate & FET & Economics \\
\hline TE3 & Professor & GET & $\begin{array}{l}\text { Inclusive } \\
\text { education }\end{array}$ \\
\hline TE4 & Doctorate & GET & Psychology \\
\hline TE5 & Doctorate & FET & $\begin{array}{l}\text { Curriculum } \\
\text { Development }\end{array}$ \\
\hline TE6 & Honors & FP & Geography \\
\hline TE7 & $\begin{array}{l}\text { Completing } \\
\text { Doctorate }\end{array}$ & FP & $\begin{array}{l}\text { Natural } \\
\text { Science }\end{array}$ \\
\hline TE8 & $\begin{array}{l}\text { Completing } \\
\text { Masters }\end{array}$ & FET & History \\
\hline
\end{tabular}


were designed to ensure that appropriate information was elicited, but also to allow for unanticipated responses and facilitate a more detailed exploration of views that may contribute significantly to the data. The interviews were conducted to gather data on what technologies participants were using and how they were using digital technology in preparing PSTs to teach with digital technologies.

During the one-on-one interview the teachers were further asked whether the institution was supporting and providing them with professional development on the use of digital technology. All the interviews with the TEs were audio recorded after receiving the consent from the participants. The audio-recorded interviews were transcribed verbatim, coded and analysed with Atlas.ti ${ }^{4}$ to identify patterns and emergent themes.

\section{Participant Observation}

To triangulate the data, four participating TEs voluntary accepted to be observed as a follow-up of the one-on-one interviews. The researchers were interested in observing how TEs were appropriating learning theory with technology integration frameworks. In their pre-service teacher preparation using the available technologies. The researchers used an observation guide to check the presence of various attributes of the conceptual frameworks. Field notes were used immediately after the observation to write up quick observations. The researchers were non-participant observers; in order to mitigate disturbances they blended into the natural setting with sustained observation. Participants were observed seven times until the observations revealed nothing new.

\section{Data Analysis}

In making sense of participants' views and opinions on integrating technology in PSTs preparation, the first step, the researchers took was to organise the data (Best \& Khan, 2006, p. 270). The second step, which consisted of observations notes and interview transcripts that were coded using TPACK and SAMR corresponding patterns, themes and categories. Regular similarities were thematically analysed by deducing from the words being examined, what is significant, or from the repeatedly used phrases which formed patterns. The researchers also wrote conceptual memos representing the conceptual insights that emerged from engagement with the data. In this phase the researcher sought to describe the various related aspects of the study. Final step was interpreting of the findings and answering the study's questions by attaching significance the results with the conceptual framework (Maxwell, 2008; Cohen et al., 2007).

\section{Ethical Considerations}

Ethical clearance was obtained from the institution's ethics research committee of the faculty of education and the department gate keepers for permission to conduct the study. Permission to record the conversations with the TEs was also obtained from every participant taking part during the interviews. For anonymity, no identification was used in the reporting of the findings, the participating TEs were allocated pseudocodes e.g. TE1, TE2, TE3, etc.

\section{FINDINGS AND DISCUSSION}

Teaching is a complex combination of educators' content knowledge in their teaching disciplines, how they envision teaching the concepts, and tools they use to bring about learning. Shulman (1986) stressed the importance of how these components work together rather than treating them as separate entities. Mishra and Koehler (2006) extended Shulman's PCK model by adding technology as a knowledge that teachers require in the modern digitalised classrooms.

The interviews solicited data on how TEs were using digital technology in teacher preparation, institutional digital support facilities and their understanding and implementation of this study's conceptual frameworks. The following were themes that emerged and linked to appropriation of the constructs: 
- Technology mediated teaching strategies;

- Content specific instructional technology;

- Professional development and educational technology;

- TPACK-SAMR in the pre-service teacher preparation.

\section{Technology Mediated Teaching Strategies}

TPK is central to educator's conception of the use of technology in support of teaching and learning content (Graham, Borup, \& Smith, 2012; Voogt \& McKenney, 2017). In other words, TPK is an educator's unique knowledge of pedagogically appropriate uses of technology, that incorporates the ways technology is used to present content so that it is understandable to students through the most useful illustrations, demonstrations, analogies, and presentations (Guerrero, 2010). In this case, it implies the TEs ability to analyse the benefits of technology based on what learning objectives have been set to be achieved.

Communication is of paramount importance in education. Studies have demonstrated communication as an important component of the educational process and context (Anderson, 2003). The 21 st century communication encourages a shift from the traditional teacher-centered to digital learner-centered strategies in order to develop the 4Cs. TE7 in the study indicated how they are using technology in communicating with the students:

... I always send announcements, post notes, send remainders... and we also have a class WhatsApp group for instant communications. In history we interact a lot with each other.

TE7 revealed their ability to integrate technology, however, they were appropriating the TPACK and SAMR constructs at an enhancement level as the technology is mainly used for one-way communication as the TE uses it to send course material to students. In other words, TEs are using the digital technology at substitution and augmentation levels. However, the researchers reason it is important to upgrade TEs' TK application beyond substitution purposes. In this context, the researchers reckon that the institution needs to empower the TEs to use their TK to yield higher level outcomes by starting from the knowledge they know to the newer TPACK driven interventions. This implies that TEs are in need of proper TPACK intervention skilling for them to move from enhancement to transformation levels in their teacher preparation programs. Interestingly, TEs are motivated to use technology when they can see the direct benefit, in meeting their curriculum learning goals as TE4 clearly pointed out that technology available should be relevant to their need:

I use technology when it's relevant to meet my learning goals, well in most cases I use PowerPoint to present teaching notes and post these on Blackboard, this has revolutionised my teaching as I maximise my class time on discussions more.

Therefore, the researchers reckon TEs appropriate what they can easily relate with, such as whiteboard and PowerPoint presentation. In this case, educational technology support staff should explore advanced PowerPoint features that TEs can explore to move from enhancement to transformation. It is also important to approach technology interventions by addressing specific needs and not just implementing general applications.

In this study, the researchers witnessed TEs including video and simulations in their lesson presentations, which according to SAMR they have moved from substitution to augmenting. This implies that educators are progressing with appropriating the technology into their daily practices, however, more can be done to progress to transformation. Mishra and Koehler (2008) relate TPACK as a knowledge domain that educators need to acquire in order to enhance and transform learning for them to achieve their learning goals. Given the appropriate and relevant training, 
as one participant suggested, will see them appropriating technology in line with constructivist student-centered strategies.

Studies revealed that students construct knowledge through interaction with others (Anderson, 2003). TE2 assigned students with group activities that assessed task interactions:

... on the high project assessment, students are required to produce as part of their portfolio a print out of their on-task or off-task WhatsApp interactions ...

In order for such technology-mediated group activities to be successful the role of a group leader is considered central, which was supported by TE2 who claimed that group interactions are influence by the group leader's initiatives to direct conversation. According to Henrie (2016) interactions keep students motivated, it therefore becomes the leaders role to ensure that interactions stay relevant and focused to the tasks objectives by redirecting of thoughts and ideas. This encourages group members to develop their interpersonal skills through negotiation of ideas with others.

The sub-theme sharing of learning resources emerged as TEs mentioned that they were using Blackboard (BB) for sharing and uploading PDF notes, handouts as well as several other learning resources such as YouTube video, PowerPoint presentations. In this case, the BB was being used as a repository of information for students. There was little evidence that TEs were using digital technology for collaboration, creativeness and critical thinking as revealed by limited strategies and applied teacher-centered traditional strategies.

\section{Content Specific Instructional Technology}

Content-specific instructional technology involves linking technology with specific curriculum for instructional purposes. Generally, content specific instructional technology is classified as technology designed for use in a specific subject. From the context of TPACK framework this constitutes the Technological and Content knowledge (TCK) construct. TCK domain dictates that teachers should have a deeper understanding of how the content matter can be easily mediated by purposeful appropriation of digital technology application. However, studies have hinted that educators focus on using the technology without maximizing its affordances to teaching the content (Mcgrath et al., 2011). In this paper, drill and practice, tutorial, and simulation were TCK functions identified from TEs interviews. TE1 and TE7 mathematics and science education were observed employing these technology-enhanced content-specific tools.

\section{Use of Tutorial Instructional Technology}

Tutorial instructional technologies give students an entire concept sequence, similar to teacher-led concept instruction (Roblyer \& Doering, 2014). TE1 educator mentions how she uses Smartboard in-build mathematics tutorials in her teaching:

Unfortunately, our Smartboard in our lecture room is not working, but I used to use Mathematics programs to teach concepts. My students would grasp concepts quickly ... but I used to use it a lot to build my lectures and students enjoyed and learned... now we are back to PowerPoint and the chalk \& talk.

The above TE1 asserts that students view mathematics instructional technology (TCK) as effective in helping them to understand, probably because tutorial applications are user controlled and self-paced offering students the flexibility to review and repeat explanations. Khan (2011) confirms that when teachers are able to design TPACK integrated lessons, students learning is enhanced. Although subject tutorial instructional technologies provide self-contained and self-paced instructions, constructivist critics posit that tutorial do not allow learner to generate contextual knowledge. Furthermore, 
instructional technologies offer only one strategy approach and sometimes do not accommodate diverse learning styles based on context (Webb \& Cox, 2004). On the other hand, advocates for instructional technology insist that they offer personalised learning and make learning more efficient by reducing cognitive loads (Nusir, Alsmadi, Al-Kabi, \& Sharadgah, 2013; Sorden, 2005).

Although TE1 was using the Smartboard instructional technology to facilitate learning, unfortunately the lack of technical support was a hindrance by failing to resolve technical problems. This points to lack of technical support, which in most cases leaves TEs frustrated. This implies that institution must have strategies in place for consistent and scheduled maintenance of technical equipment. The TE indicated how she is back to the enhancement traditional strategies using PowerPoint and other digital tools at her disposal to dispense content.

By allowing teachers to design and generate content knowledge, technology has given educators control and power to generate their own context related content quickly and efficiently within their learners' setting. TE1 reported:

... my course is very broad and have to reconceptualise some content material, hence I use PowerPoint to present my own content created from scratch. I keep updating these notes by adding and removing some content but ummmm mostly it's basically updating relating to current researches and linking to their contexts.

This demonstrates Mishra and Koehler's (2008) TCK component; in this case the technology and content knowledge domains are merged to create a technology enhanced content delivery. TE1X used the technology for both content and pedagogical reasons. In context of TCK TE1 had this to say:

We used graphmatica, this is a graphing tool which allows me teach functions and algebra interactively in the lecture. e.g. one can change variables and students can describe and conjecture about changes in the graph ... also use Geogebra to help pre-service teachers comprehend geometry. All these we installed on the Smartboard

This TE1 also highlighted their use of Khan Academy which is a free online tutorial and affords both content and pedagogy goals. Interestingly, TEs are currently using PowerPoint self-generated or sourced from the internet for both content and pedagogical strategies.

TCK entails educators have knowledge about content specific technologies and how to use it to represent concepts as well as research and create the content in different ways.

\section{Technology-Enhanced Simulations for Content Knowledge}

Technology-enhanced simulations are computerised modelling of abstract concepts on how to do something (Roblyer \& Doering, 2014), i.e. how to bisect a frog in Natural Science class. TE7, in their PSTs preparation used simulation to teach about and demonstrate a concept TE7 indicated that:

I have started to use video that demonstrates science concepts... ...this amazing YouTube respiratory system five-minute video... When I am now introducing an abstract or complex science concept, I now look for simulated video that explains it with motion and pictures.

TE7 further indicated that simulation helps him model complex processes. Alessi and Trollip (2001) summarised the potential benefits of simulation in learning as making holistic observations that could naturally stretch over a long period of time. They further indicate that students can safely engage with tasks that would otherwise be dangerous and volatile in real life. Simulations afford students an experiential form of learning in a safe and cost-effective manner. Grim, Rosenberger, Rosenfeld, Anderson, and Eason, (2013) argue that some educators are replacing hands-on, in class 
activities with virtual simulation thereby diminishing experiences of hands on learning resulting in inaccurate or imprecise perspectives on system complexities by students. Nevertheless, educators acknowledge the instructional usefulness of simulations (Prensky, 2007), especially in resource deprived environments. Researchers argue that simulations should be used to supplement regular lab sessions (Makransky, Thisgaard, \& Gadegaard, 2016; Man-Wai, 2017).

TE7 also indicated by saying:

I use YouTube videos for both content delivery and discussion based on different topics within science education.

The above statement agrees with other studies that reveal that YouTube and simulated videos have the potential to be used as supplemental instructional tools (Bates, 2015; Jokobsdottir, Mckeown, \& Hoven, 2010; Potkonjak, Gardner, Callaghan, Mattila, Guetl, et al., 2016). Videos have been shown to be effective for learning. Students are able to develop higher level thinking skills such as critical analysis and problem solving, as well as start discussions (Prensky, 2007).

\section{Technology-Enhanced Drill and Practice}

Drill and practice instructional technologies provide students with illustrated activities followed up by exercises that provide instant feedback. This technology-enhanced teaching practice emphasises traditional directed teaching strategies (Roblyer \& Doering, 2014). TE1 shared that they use Mathematics applications that help students' master mathematical concepts:

I have realised that Maths application help students master basic and complex concepts. I am advising students to use some of the Maths programs to practice as it give them problems and then reveal solutions.

A Natural science TE also asserted:

When I went to a conference one presenter presented on computer programmes that teach students concepts, I came back and hunted them, my friend from the school gave me a CD that teaches on photosynthesis and I used it in class on the Smartboard ... (giggling) it was fun and students enjoyed the lesson. ... Now my worry is our students here are not exposed to such programs and they might not know...

The sentiment expressed above shows that TEs are starting to realise the potential of technology and are learning to use it in their pre-service teacher preparation programmes by allowing students to learn concepts on their own using technology. However, technology enhanced drill and practice strategies also possess traditional elements as they do not allow the student to think outside of the given context. The researcher therefore argues that these approaches not be used in isolation. They are useful for personal time learning and mastering of concepts, therefore they can be given to students for practice outside of the classroom so they can learn at their own pace.

\section{Professional Development and Educational Technology Skilling}

All participating TE except one pointed to the professional development implemented by the Fundani 5 and e-learning center (Training and development facilities employed at the study cite) as generic and difficult to link their relevance to their actual practices in pre-service teacher preparation. Therefore, making it difficult to implement what they were trained due to lack of subject specific demonstrations. They also pointed to the lack of hands on experience, claiming that there are always expert-centred 
demonstrations. TE4 indicated that there's need for training on specific instructional software for faculty of education staff:

I never learnt computers at school, but I feel that assuming that we all can master this technology at the same pace (laughs) I know some of my colleagues who cannot type, let alone switch their machines on. This expectation that we must use technology is like trying to ride a dead horse (laughs). We need trainers who are patient and knowledgeable of teaching theories ... they teach me how I can use the computer in teaching history and English...

The above extract shows that even though there are professional developments, they are irrelevant interventions that do not address subject specific needs. TEs are more willing to integrate technology if it assists them in achieving their specific instructional goals. The TEs technology related professional development programmes need to help TEs develop the intermediate forms of technology integration frameworks which relate directly to their everyday pre-service teacher preparation practice. On the contrary, TE3 refuted the argument saying that the staff development has taught them how to use the technology in general and later domesticate it to her specific needs:

Ifeel the professional development the institution, in particular by Fundani are ok but there is room for improvement. The one I managed to attend helped me on my technology knowledge. The blackboard one was good though I need more time to practice without making a fool of myself (laughs) ...

There is need for professional development interventions to cater for different learning styles among the TEs as indicated from the feedback above. Professional development initiatives are encouraged to strategise and implement programmes that are flexible to accommodate the diverse learning styles of the TEs and include evaluative support follow-ups.

\section{TPACK-SAMR in Pre-Service Teacher Preparation}

Pre-service teacher training should be built on a philosophical framework around teaching with technology and progress into applying technology integration in teacher training programmes. This approach allows PSTs time to get comfortable with integrating technology into their pedagogical approaches (Stokes-Beverley \& Simoy, 2016).

TEs in this study, although not being mountain climbers to the peek, they plan the course and choose the best tools possible to construct the best experience in the given context. Lesson observation revealed TEs using digital technology congruent to their traditional practices.

When asked about their TPACK knowledge and adoption, TE1 summed up by saying:

Although I am not an expert in technology and teaching, my experience in teaching entails that I set objectives to achieve a particular concept that learners must achieve at the end of a given time. ummmmm ... Depending on the technology at ones' disposal and knowhow, firstly, I use technology to design and develop my content. I have used some Mathematics program that helps students' master mathematics concepts. Some of the programs test students understanding and students can repeat as when one needs... As well as use it as teaching tool bearing in mind technology is there to enrich the students learning process... How I can increase my efficiency...

TE2 had this to say:

I use WhatsApp for a project I am doing with schools. Students (PSTs) are given high school students to work with and are creating WhatsApp groups to staying in touch and keeping progress of each 
other. The groups work together, WhatsApp allows the anytime, anywhere discussions. I realised that using WhatsApp has increased engagement within the group member...

The above extract reveals how TEs are appropriating TPACK and SAMR frameworks to reach transformation levels and becoming TPACKed educators (see Figure 1). Researchers indicate that TPACK guides educators on which technological tools and processes are a good fit to achieve the learning goals (Baran, Canbazoglu Bilici, Albayrak Sari, \& Tondeur, 2017; Koh, Chai, \& Tsai, 2013; Kurt, 2014). Therefore, balancing the TPACK constructs holistically, is moving from techno-centric to learner-centric strategies. SAMR's first two levels of progression from substitution through to augmentation can be observed from that data. However, a learner-centric professional development approach will help TEs realise the redefinition level that allows for previously inconceivable forms of teaching and learning. Therefore, it is important that institutions and TEs adopt philosophical frameworks, guided by teaching and learning theory, in their subject disciplines. This approach on pre-service preparation programmes allows TEs to model to PSTs theory and technology integrated pedagogical approaches.

\section{CONCLUSION}

This study set out to examine how TEs are appropriating teaching with technology in their pre-service teachers training practice. The findings indicated that most TEs were indeed making use of technology however, it was mostly at low ranking level such as substitution and augmentation as per the SAMR model. Technology is currently being placed into their existing traditional structures rather than being recognised for the innovative possibilities it can create. TE's were analysed as not being purposive about their use of technology with regards to achieving higher level outcomes. The failure by most TEs to achieve transformation was mainly due to their failure to practically adopt any contemporary learning theories and technology integration frameworks. This shortcoming was also found to be applicable to institutions as they have no clear policies in place that state and govern the adoption of these constructs. Furthermore, sustainable challenges such as lack of technical support continue to hinder technology integration. The researchers encourage institutions to not only provide technological resources but maintain and upgrade them continuously. Relevant professional development as well as inadequate technology resources continue to frustrate and dissuade TEs effective integration of technology. TEs are encouraged to desist from gatekeeping traditional strategies in the name of lack of theoretical basing but are instead encouraged to appropriate the richness of technology in $21^{\text {st }}$ century contexts.

Based on the findings of this study, the researchers suggest professional development be used to facilitate TEs' reflection on how technology can be incorporated to enhance their instructional strategies. The researchers further recommend teacher preparation institutions to provide discipline specific professional development to TEs on transformative technology mediated interventions. More specifically, they should engage educational technology experts knowledgeable in learning theories in the faculty.

The limitation of this study is that the TEs were from the same institution. It would be interesting to determine if TEs in other institutions produce similar results. The researchers also suggest further research to gain a better understanding of how TEs utilise different technology integration constructs on subject specific context.

\section{DISCLAIMER}

This paper is extracted from an unpublished Doctorate thesis at the date of submission. 


\section{REFERENCES}

Alessi, S. M., \& Trollip, S. R. (2001). Multimedia for learning: Methods and development (3rd ed.). Boston: Pearson Education.

Ally, M., \& Tsinakos, A. (2014). Increasing Access through Mobile Learning. Commonwealth of Learning and Athabasca University, Vancouver. Retrieved from http://www.col.org/PublicationDocuments/pub_Mobile Learning_web.pdf

Anderson, T. (2003). Getting the Mix Right Again: An updated and theoretical rationale for interaction. International Review of Research in Open and Distance Learning, 4(2). doi:10.19173/irrodl.v4i2.149

Baran, E., Canbazoglu, S., Albayrak, A., \& Tondeur, J. (2017). Investigating the impact of teacher education strategies on preservice teachers' TPACK. British Journal of Educational Technology. doi:10.1111/bjet.12565

Bates, A. W. (2015). Teaching in a Digital Age: Guidelines for designing teaching and learning for a digital age. Retrieved from https://opentextbc.ca/teachinginadigitalage/

Chigona, A., \& Chigona, W. (2013). South African pre-service teachers' under-preparedness to teach with Information Communication Technologies. IEEE Xplore. Retrieved from http://ieeexplore.iee.org/stamp/stamp. jsp?tp=\&arnumber $=6644381$

Enochsson, A. B., \& Rizza, C. (2009). ICT in initial teacher training: research review. OECD. doi: $10.1787 / 220502872611$

Graham, C. R., Borup, J., \& Smith, N. B. (2012). Using TPACK as a framework to understand teacher candidates' technology integration decisions. Journal of Computer Assisted Learning, 28(6), 530-546. doi:10.1111/j.13652729.2011.00472.x

Grim, P., Rosenberger, R., Rosenfeld, A., Anderson, B., \& Eason, R. E. (2013). How simulations fail. Synthese, 190(12), 2367-2390. doi:10.1007/s11229-011-9976-7

Guerrero, S. (2010). Technological Pedagogical Content Knowledge in the Mathematics Classroom Abstract. Journal of Digital Learning in Teacher Education, 26(4), 132-139. doi:10.1080/10402454.2 010.10784646

Henrie, C. R. (2016). Measuring Student Engagement in Technology-Mediated Learning Environments. Brigham Young University. doi:10.1016/j.compedu.2015.09.005

Jokobsdottir, S., Mckeown, L., Hoven, D., Jakobsdottir, S., Mckeown, L., \& Hoven, D. (2010). Teacher education through Open and Distance Learning. (P. A. Danaher \& A. Umar, Eds.). British Columbia: Commonwealth of Learning. Retrieved from ww.col.org

Kihoza, P., Zlotnikova, I., Bada, J., \& Kalegele, K. (2016). Classroom ICT integration in Tanzania: Opportunities and challenges from the perspectives of TPACK and SAMR models. International Journal of Education Ad Development Using Information and Communication Technology, 12(1), 107-128.

Koehler, M. J., \& Mishra, P. (2009). What is Technological Pedagogical Content Knowledge (TPACK)? Contemporary Issues in Technology \& Teacher Education, 9, 60-70. doi:10.1016/j.compedu.2010.07.009

Koh, J. H. L., Chai, C. S., \& Tsai, C. C. (2013). Demographic factors, TPACK constructs, and teachers' perceptions of constructivist-oriented TPACK. Journal of Educational Technology \& Society, 17(1), 185-196.

Kurt, G. (2014). TPACK in practice: A qualitative study on technology integrated lesson planning and implementation of Turkish pre-service teachers of English.

Makransky, G., Thisgaard, M. W., \& Gadegaard, H. (2016). Virtual simulations as preparation for lab exercises: Assessing learning of key laboratory skills in microbiology and improvement of essential non-cognitive skills. PLoS One, 11(6), 1-11. doi:10.1371/journal.pone.0155895 PMID:27253395

Man-Wai, C. (2017). Using Computer Simulated Science Laboratories: A Test of Pre-Laboratory Activities with the Learning Error and Formative Feedback Model. University of Alberta. 
Mcgrath, J., Karabas, G., Willis, J., John, S., College, F., \& Rochelle, N. (2011). From TPACK Concept to TPACK Practice: An Analysis of the Suitability and Usefulness of the Concept as a Guide in the Real World of Teacher Development. International Journal of Technology in Teaching and Learning, 7(1), 1-23.

Mishra, P., \& Koehler, M. J. (2006). Technological Pedagogical Content Knowledge: A framework for teacher knowledge. Teachers College Record, 108(6), 1017-1054. doi:10.1111/j.1467-9620.2006.00684.x

Nusir, S., Alsmadi, I., Al-Kabi, M., \& Sharadgah, F. (2013). Studying the impact of using multimedia interactive programs on children's ability to learn basic math skills. E-Learning and Digital Media, 10(3), 305-319. doi:10.2304/elea.2013.10.3.305

Potkonjak, V., Gardner, M., Callaghan, V., Mattila, P., Guetl, C., Petrović, V. M., \& Jovanović, K. (2016). Virtual laboratories for education in science, technology, and engineering: A review. Computers \& Education, 95, 309-327. doi:10.1016/j.compedu.2016.02.002

Puentedura, R. R. (2009). Learning, Technology, and the SAMR Model: Goals, Processes, and Practice [blog post].

Roblyer, M. D., \& Doering, A. H. (2014). Integrating Educational Technology into Teaching. (Sixth). Essex: Pearson Education. Retrieved from www.pearsoned.co.za

Sang, G., Tondeur, J., Chai, C. S., \& Dong, Y. (2014). Asia-Pacific Journal of Teacher Validation and profile of Chinese pre-service teachers' technological pedagogical content knowledge scale. Asia-Pacific Journal of Teacher Education, 37-41.

Sorden, S. D. (2005). A Cognitive Approach to Instructional Design for Multimedia Learning. Informing Science Journal, 8, 263-279. doi:10.28945/498

Stokes-Beverley, C., \& Simoy, I. (2016). Advancing Educational Technology in Teacher Preparation: Policy Brief. Office of Educational Technology, US Department of Education.

Strauss, S. (1993). Teachers' Pedagogical Content Knowledge About Children's Minds and Learning: Implications for Teacher Education. Educational Psychologist, 28(3), 279-290. doi:10.1207/s15326985ep2803_7

Tondeur, J., Pareja Roblin, N., van Braak, J., Voogt, J., \& Prestridge, S. (2017). Preparing beginning teachers for technology integration in education: Ready for take-off? Technology, Pedagogy and Education, 26(2), 157-177. doi:10.1080/1475939X.2016.1193556

Tondeur, J., Roblin, N. P., van Braak, J., Fisser, P., \& Voogt, J. (2013). Technological pedagogical content knowledge in teacher education: In search of a new curriculum. Educational Studies, 39(2), 239-243. doi:10. 1080/03055698.2012.713548

Tondeur, J., Van Braak, J., Sang, G., Voogt, J., Fisser, P., \& Ottenbreit-leftwich, A. ... Ottenbreit-Leftwich, A. (2012). Preparing pre-service teachers to integrate technology in education: A synthesis of qualitative evidence. Computers \& Education, 59(1), 134-144. doi:10.1016/j.compedu.2011.10.009

Voogt, J., \& McKenney, S. (2017). TPACK in teacher education: Are we preparing teachers to use technology for early literacy? Technology, Pedagogy and Education, 26(1), 69-83. doi:10.1080/1475939X.2016.1174730

Webb, M., \& Cox, M. (2004). A review of pedagogy related to information and communications technology. Technology, Pedagogy and Education, 13(3), 235-286. doi:10.1080/14759390400200183

\section{ENDNOTES}

1 A teacher educator (TE) is a professional who trains pre-service teachers by educating them on teaching and learning theories, strategies and principles towards a professional teacher qualification. Pre-service teachers (PSTs) are trainee teachers who are undergoing a four-year professional teacher training programme with regards to teaching and learning theories, strategies and principles in teaching.

3 A TE who has mastered all the knowledge domains of TPACK and can use them for effective teaching with technology.

4 ATLAS.ti is a qualitative data analysis \& research software https://atlasti.com/

$5 \quad$ Fundani is a training facility that serves the University by initiating and facilitating higher education development to enhance teaching and learning. 
Nyarai Tunjera is currently writing up her Ph.D. in educational technology with Cape Peninsula University of Technology. In her undergraduate, she majored in Computer Science and Education. Her publications include: mobile-mediated learning, e-learning and ICTs in higher education. She has presented full papers in international conferences. Her passion is seeing digital technology being domesticated in the teaching and learning in Higher Education institutions. Furthermore, she is passionate on modelling women in STEM subjects in developing contexts. 